\title{
Ferrer Beltrán, Jordi. Prueba sin convicción. Estándares de prueba y debido proceso. Madrid: Marcial Pons, 2021.
}

\author{
Jordi Nieva-Fenoll \\ Departamento de Derecho Procesal \\ Universitat de Barcelona
}

Fecha de recepción 13/04/2021 I De publicación: 24/06/2021

Cuentan que hacia finales de 1974, Stephen Hawking le apostó a su colega Kip Thorne que los agujeros negros no existían. Si ganaba Hawking, recibiría una suscripción de cuatro años a la revista satírica Private Eye. Si ganaba Thorne, Hawking le pagaría una suscripción de un año a la revista erótica Penthouse. Varios años después, Hawking decidió pagar la apuesta. La anécdota tiene otros detalles divertidos y es relatada por el propio Hawking en su "Historia del tiempo". En 2017, Thorne ganó el premio Nobel. Hawking falleció poco después tan laureado y reconocido como su colega, aunque sin el Nobel. No creo que le importara. Tuvo grandes e inspiradoras ideas, pero no hizo algo como probar la existencia de las ondas gravitacionales.

Yo no me he jugado nada en firme con mi amigo y admirado Jordi Ferrer con respecto a la existencia de los estándares de prueba, más allá de comidas o cenas con las que ya nos agasajamos sin necesidad de apostar. Tampoco íbamos a ganar ninguno de los dos el Nobel, aunque existiera para juristas, pues para desgracia nuestra no tenemos ninguno de los dos las mentes de los anteriormente citados. Sin embargo, existen algunos paralelismos curiosos con la historia relatada.

Ferrer y yo hemos trabajado mucho en favor de la racionalización de la actividad probatoria en un proceso judicial. Casi desde sus inicios doctrinales ha intentado sacar a esa actividad del subjetivismo del juez. E idéntica cosa hemos intentado otros y yo mismo en los últimos años. En el libro que ahora comento -“prueba sin convicción”-, Ferrer pasa cuentas con todos nosotros. Con Daniel González Lagier, con Marina Gascón Abellán, con Ronald J. Allen, con Larry Laudan o conmigo mismo, entre otros. Y lo hace con la contundencia propia de la amistad que nos profesamos y con un desparpajo que sólo he observado en materia jurídica con carácter general entre filósofos del Derecho. Por desgracia no es así habitualmente en el resto de materias, dado que esa conducta puede causar - ¡aún a estas alturas!un casus belli. Jordi nos dice claramente, y varias veces, que nos equivocamos, y nosotros creemos que es él quien se equivoca en diversos puntos y así se lo hemos dicho en público y en privado con frecuencia. 
Y bendita discrepancia, porque nos permitirá seguir debatiendo, que es otro modo de investigar no tan practicado pero muy fructífero, siempre que se venza la timidez, se diga lo que se piensa y no se utilice la retórica o se hable por hablar.

Ferrer cree que los estándares de prueba existen, y yo también. Él cree que son una vía de mejora muy relevante de la actividad probatoria en un proceso, y yo también lo creo aunque sólo en una mínima parte, y por ello percibo que su teoría está cargada de buenas intenciones. Con un esfuerzo de objetivación encomiable -aunque insuficiente, como demostraré- formula hasta siete estándares de prueba, desde el más exigente al más sencillo de cumplir.

Con esos estándares intenta guiar la labor judicial, y esa es la única parte que me seduce -en parte- de los mismos. Cada uno de los siete son una auténtica pauta de cómo debe comportarse un juez en un proceso a la hora de considerar un hecho como probado. Una vez cumplida esa labor, es posible según nos cuenta Ferrer- que la versión de una de las partes y la versión de la otra hayan alcanzado el nivel del mismo estándar, momento en el que se produciría un empate y habría que proceder a un reparto del riesgo de errores que sería operado gracias a la carga de la prueba, que nos señalaría quién debe perder el proceso en esa situación de igualdad, o bien gracias a las presunciones -o presunciones aparentes incluso- que imponen una versión favorable a una de las partes en caso de persistir la referida incertidumbre.

El esfuerzo argumentativo de Ferrer es muy notable y netamente lógico en su formulación. Pero a mi juicio es defectuoso en su base. Personalmente he intentado constantemente acercar los conocimientos extrajurídicos al estudio del Derecho, pero nunca he pretendido comparar en términos estrictos los métodos utilizados por otras ciencias con los que empleamos en la ciencia jurídica. En cambio, Ferrer sí compara expresamente la actividad probatoria con la diagnosis médica, la farmacología o incluso la paleontología.

Partiendo de ese fundamento, no se hace extraño su recorrido posterior, que ya ha sido descrito anteriormente. Mi amigo busca una prueba diagnóstica similar a una tomografía axial computerizada, y querría -también lo desearía yo- que esa diagnosis arroje imágenes que demuestren, por ejemplo, la existencia de un tumor. Él desea localizar un fármaco que funcione en el 95\% por ciento de los casos, sopesando los riesgos de mantener el mismo en el mercado habida cuenta que al 5\% de los pacientes, según rigurosos datos estadísticos, o no los cura o los mata. Este filósofo del Derecho parece querer alejar 
al Derecho de la Filosofía, y si es así tiene mi aplauso, porque hace ya mucho tiempo que tendría que haberse dado ese salto, aunque en el caso del Derecho sin dejar de lado algunas bases filosóficas que seguirían siendo interesantes pese a que se llegara a ese resultado.

Sin embargo, olvida Jordi Ferrer con estas ideas que los diagnósticos médicos no sólo tienen una base estadística, sino que con frecuencia evidencian sin recurrir a esos cálculos la presencia de una patología, lo que aleja a la medicina de la incertidumbre y la acerca a la verdad, esa meta del Derecho probatorio, inalcanzable según tantos autores. Lo mismo sucede con la farmacología y la paleontología. Varias de sus conclusiones son ciertas, sin matices, sin ningún género de dudas. Una ventaja enorme para dichas materias, aunque siguen poseyendo un tremendo espacio para las hipótesis, como no puede ser de otro modo en la ciencia.

En el proceso judicial la situación es muy distinta. No suele haber certezas, aunque sí que están presentes a veces, al contrario de lo que acostumbra a afirmarse con vocación un tanto mítica, casi teológica. El juez puede constatar la presencia de un cadáver, y que ese sujeto está muerto es una certeza que en absoluto es irrelevante para el enjuiciamiento. Puede ir incluso más allá, y localizar pruebas del acaecimiento de un hecho sin lugar a ninguna duda. El asesinato de Lee Harvey Oswald lo perpetró Jack Ruby, y de eso no hay duda alguna. Todos hemos visto las imágenes. En cambio -por poner un ejemplo que mezcle la medicina con el Derecho-, pese a las veces que se le ha motejado como demente, no podemos estar seguros de que Adolf Hitler sufriera una enfermedad mental que hubiera podido absolverlo en un proceso penal. Unas imágenes parecen revelar la enfermedad de Parkinson, y sus decisiones y forma de expresarse apuntan a un grave trastorno de la personalidad, pero nada de esto se puede decir con seguridad. Y ante esas dudas, tal vez hubiera que haber absuelto a Adolf Hitler de crímenes contra la humanidad, lo que con seguridad no hubiera sido aceptado por ninguno de nosotros.

¿Por qué? Aquí está la clave de toda esta materia, y apunta a ella Ferrer en algunos pasajes de su obra. Eliminar el subjetivismo es difícil, y además no hay que olvidar que todas nuestras categorizaciones en materia probatoria están construidas sobre la base de ese subjetivismo, no hay que olvidarlo. En Roma no se le prestó demasiada atención a este tema, hasta el punto de que dejaron la materia probatoria en manos, no del praetor, sino de la población indígena conquistada en el proceso formulario. Les empezó a preocupar más en período clásico y postclásico, cuando los jueces reasumieron la labor probatoria. Pero cuando los burgueses universitarios del siglo XII visualizaron que serían los jueces designados por nobleza y realeza los que resolverían sus causas, crearon el secundum allegata et probata (partium), el 
sistema legal de valoración de la prueba y la propia institución de la carga de la prueba como llegó a nuestros días. De esa manera, atenazaron al juez a lo que le dijeran las partes. Una auténtica "lucha de clases" fuera de época. Principios dispositivo y de aportación de parte. Esas mismas bases inspiraron el sistema adversarial en el mundo del Common Law, como es fácilmente identificable. Dicho de otro modo, se eliminó el subjetivismo de un plumazo porque no se confiaba en aquellos jueces. Con toda la razón.

Pero en ese mundo del Common Law fue tomando protagonismo, casi al mismo tiempo, el jurado. Y justamente de su labor derivó el estudio moderno de la prueba. El jurado no podía estar sometido al régimen de valoración legal, porque no conocía el Derecho. Por ello, los jurados debían hallar su veredicto según "the best of their knowledge", como dijo Blackstone. Y ni siquiera se motivaba el veredicto, puesto que habiendo prestado juramento estaban inspirados por Dios, de quien no cabía dudar. Ese fue el sistema que propuso Bentham para Francia y ese es el sistema de la intime conviction, también citado por Ferrer. Basta leer a Bentham para darse cuenta de que este autor, igual que ya había ocurrido hacía siglos, confiaba en la intuición de los jueces para averiguar la realidad de los hechos a través de la gestualidad de los testigos y de las partes, y poco más. De ahí vino también, por cierto, la obsesión por la oralidad. Y ese es el origen de todo lo que ha venido después: puro subjetivismo, sólo limitado por la persistencia tenaz de algunas antiguas -y absurdas- reglas de prueba legal.

A pesar del empirismo radical de Bentham y de su voluntad de acercar al Derecho al mismo como entusiasta de la ley escrita -sabido es que en su país no le hicieron caso-, tal vez los siglos XVIII y XIX no daban para más en ese esfuerzo empírico y no hubo otro remedio que acomodarse con el subjetivismo en materia de prueba. E insisto, de ese subjetivismo parte todo nuestro sistema. Jordi Ferrer, o yo mismo, intentamos cambiar precisamente esta situación, no porque no nos fiemos de los jueces, sino porque pensamos - creo coincidir en esto con Ferrer-que un litigante merece algo más que una respuesta intuitiva de un juzgador.

Por mi parte he procurado desvelar las ciencias que se hallan detrás de los medios de prueba: psicología del testimonio, semiótica textual y todas las que atañen a los dictámenes periciales. Y también he estudiado el subjetivismo judicial desde la psicología cognitiva a través de los heurísticos y los sesgos. Ferrer, sin despreciar en absoluto nada de lo anterior, se propone dar un paso más: reglar la labor de enjuiciamiento a través de los estándares, que le otorgarían -mayor-objetividad a la tarea probatoria. Y aquí es donde nuestros caminos se separan. 
Mi amigo formula los referidos siete estándares con impecable brillantez. Pero se resiste a asumir -y ojalá lo siga haciendo- que sus estándares están cargados de subjetivismo. Cuando en el primero afirma, por ejemplo, que "deben haberse refutado todas las demás hipótesis plausibles explicativas de los mismos datos que sean compatibles con la inocencia del acusado/demandado o más beneficiosas para él", parece dejar de lado que la plausibilidad de una hipótesis parte muchas veces de un juicio subjetivo basado en una noción más o menos intersubjetiva de la experiencia. O cuando en el segundo nos habla de que los datos probatorios disponibles deben integrarse de forma "coherente", se pierde de vista que la coherencia tampoco es una variable objetiva, y mucho menos cuando la utilizamos como parámetro para evaluar conductas humanas. Conforme se va descendiendo en la exigencia de plausibilidad en el escalado del resto de estándares, el subjetivismo toma paulatinamente cada vez más protagonismo.

Pero supongamos, como lo hace Jordi Ferrer, que los estándares funcionan de la forma que mi compañero apetece. Si ambas partes logran igualarse en el cumplimiento de estándares, deben utilizarse o la carga de la prueba o las presunciones -legales, por cierto-, reales o aparentes. Y nuevamente me separo de su doctrina. La carga de la prueba en su versión clásica, la única que probablemente tuvo hasta el siglo XIX y la más frecuentemente utilizada fuera del ámbito del Common Law, reparte entre los litigantes la responsabilidad de probar. En un trabajo anterior Ferrer rechazó esta versión de la carga de la prueba, pero parece volver ahora a la misma en su formulación, aunque intente más bien acomodarse en la burden of persuasion del ámbito anglosajón. Al final, estamos dividiendo los hechos de un proceso en función de quién debe probarlos, y acabamos condenando a quien no lo hace. Esa es la carga subjetiva. La objetiva parte de la subjetiva y nos señala, en el ámbito de esta segunda, cuál es el nivel o estándar probatorio que debe alcanzar cada parte, y ese es justamente el núcleo de esa carga objetiva.

Algunos autores argumentaron por ello que carga subjetiva y objetiva eran dos caras de la misma moneda, cuando en realidad lo que ocurre es que son dos estadios distintos del proceso probatorio, como explica acertadamente Ferrer. En el proceso estadounidense se ve más fácilmente porque ambas cargas se utilizan en fases procesales distintas, gracias en parte, por cierto, al jurado. Pero sucede que el segundo estadio - la carga objetiva- se acaba haciendo depender del primero -la carga subjetiva-, y en ese punto es donde creo que toda la argumentación acaba siendo errónea, más allá de que en el proceso continental ambas cargas, caso de que existan, se utilizan exactamente en la misma fase procesal: en el momento de la sentencia y sólo si la prueba no fue eficiente. Curiosamente, en el solemnis ordo iudiciarius se valoraba 
la carga -subjetiva- de la prueba al inicio del proceso, y las "medidas de prueba" al final del proceso. De forma parecida al proceso estadounidense. Dicho queda.

Lo que sucede es que actualmente en el proceso nadie tiene la responsabilidad de probar nada, tampoco a un determinado nivel, sino que las partes acuden al proceso intentando defender su posición y ganar así el proceso. No se puede imaginar ese escenario como si fuera un laboratorio, porque no lo es. Aparecen en el mismo las herramientas de los actores, las emociones del público y hasta el ánimo del director del teatro, si se me permite el parangón. Y todos esos elementos son muy difícilmente controlables y evaluables. Para que realmente lo fueran al mismo nivel que la medicina o la física, deberíamos poseer un método de valoración infalible de la credibilidad de litigantes y testigos, y ese método ni lo tenemos ni lo podemos tener, al menos en esta generación. Deberíamos también conocer todos los detalles del contexto e intenciones del autor de un documento, o al menos poseer cálculos estadísticos en torno a los mismos parecidos a los que sí existen, aún de modo insuficiente, en psicología del testimonio. O bien deberíamos poder confiar al 100\% en el parecer de un perito. Sin embargo, no tenemos nada de eso. Y por ello -también- no podemos sancionar con una condena a quien no consiguió probar un hecho, porque no es exactamente que no consiguiera probarlo, sino que no lo hizo en función del estándar que le exigimos, cuya formulación, no se olvide, era subjetiva. Como lo es también su apreciación, por mucho que Ferrer se esfuerce en guiarla, lo que insisto que es acertado en su propósito.

Por ello, he afirmado desde hace tiempo que la carga de la prueba no tiene ningún papel en el sistema de libre valoración, puesto que en el mismo ni se exige a ningún litigante aportar nada ni se evalúa la prueba en función de niveles de prueba. Al contrario, eso es lo que ocurría en el régimen legal de valoración, vuelvo a decirlo. Más que carga, la prueba era una obligación de las partes, pues eran sus propietarias en función del secundum allegata et probata. Y fueron surgiendo niveles o medidas de prueba para diferentes usos, aunque fundamentalmente para deshacer las situaciones de empate -con ese sistema se producían objetivamente, con el actual son subjetivas y marginales- dado que las pruebas se pesaban y ganaba el que obtenía un mayor volumen probatorio. Por eso se distinguía entre prueba semiplena o prima facie o prueba de indicios - las tres cosas eran lo mismo-, prueba plena e incluso prueba plenísima, y era insultantemente diáfano cuándo concurría lo primero y lo segundo, aunque no tanto lo tercero, pese a que la rúbrica plenissima lo dice todo. Comparen esos tres parámetros respectivamente con la probable cause, la preponderance of evidence y el beyond any reasonable doubt y tal vez se encontrarán con una sorpresa. Sólo les faltará la clear and convincing evidence entre los 
estándares más conocidos, dado que aún hay más. Pero si se dan cuenta de que los tres primeros son también los más antiguos, es posible que vean un paralelismo que en absoluto es infundado. Jordi Ferrer no me parece que niegue que este paralelismo existe, pero opina que no es el origen de los estándares. Yo no puedo evitar pensar lo contrario, permítanme la broma, más allá de toda duda razonable. Sucede que los estándares actuales no son tan toscos como los antiguos -las medidas de prueba-, y Ferrer intenta afinarlos aún más desde el punto de vista epistémico y metodológico. Pero pretenden exactamente lo mismo que se deseaba con aquellos del pasado: guiar al juez en la prueba de los hechos, aun con mucha mayor libertad, por fortuna.

El nuevo libro de Jordi Ferrer es una excelente noticia muy esperada. Emociona leerlo en muchos de sus pasajes. Se disfruta mucho con su ironía y vehemencia, en la que los que lo conocemos visualizamos a su persona, sonrisa y mirada. Pero con lo que realmente disfrutará el lector es con el rigor científico de sus argumentaciones. Ojalá dé mucho que hablar. Desde luego, por mí, y creo que por varios de los aludidos, no va a quedar.

Jordi: enhorabuena y gracias. 